\title{
The hydrogen peroxide-sensitive proteome of the chloroplast in vitro and in vivo
}

\section{Meenakumari Muthuramalingam ${ }^{1}$, Andrea Matros ${ }^{2}$, Renate Scheibe $^{3}$, Hans-Peter Mock ${ }^{2}$ and Karl-Josef Dietz ${ }^{1}$ *}

${ }^{1}$ Biochemistry and Physiology of Plants, Faculty of Biology - W5-134, Bielefeld University, Bielefeld, Germany

${ }^{2}$ Applied Biochemistry, Institute of Plant Genetics and Crop Plant Research, Gatersleben, Germany

${ }^{3}$ Plant Physiology, Faculty of Biology and Chemistry, University of Osnabrück, Osnabrück, Germany

Edited by: Western Australia, Australia

\section{Reviewed by:}

Martin Hajduch, Slovak Academy of Sciences, Slovakia

Georgia Tanou, Aristotle University of

Thessaloniki, Greece

\section{${ }^{*}$ Correspondence:}

Karl-Josef Dietz, Biochemistry and Physiology of Plants, Faculty of e-mail: karl-josef.dietz@ uni-bielefeld.de
Harvey Millar, The University of Biology - W5-134, Bielefeld University, 33501 Bielefeld, Germany.

Hydrogen peroxide $\left(\mathrm{H}_{2} \mathrm{O}_{2}\right)$ evolves during cellular metabolism and accumulates under various stresses causing serious redox imbalances. Many proteomics studies aiming to identify proteins sensitive to $\mathrm{H}_{2} \mathrm{O}_{2}$ used concentrations that were above the physiological range. Here the chloroplast proteins were subjected to partial oxidation by exogenous addition of $\mathrm{H}_{2} \mathrm{O}_{2}$ equivalent to $10 \%$ of available protein thiols which allowed for the identification of the primary targets of oxidation. The chosen redox proteomic approach employed differential labeling of non-oxidized and oxidized thiols using sequential alkylation with $\mathrm{N}$-ethylmaleimide and biotin maleimide. The in vitro identified proteins are involved in carbohydrate metabolism, photosynthesis, redox homeostasis, and nitrogen assimilation. By using methyl viologen that induces oxidative stress in vivo, mostly the same primary targets of oxidation were identified and several oxidation sites were annotated. Ribulose-1,5-bisphosphate (RubisCO) was a primary oxidation target. Due to its high abundance, RubisCO is suggested to act as a chloroplast redox buffer to maintain a suitable redox state, even in the presence of increased reactive oxygen species release. 2-cysteine peroxiredoxins (2-Cys Prx) undergo redox-dependent modifications and play important roles in antioxidant defense and signaling. The identification of 2-Cys Prx was expected based on its high affinity to $\mathrm{H}_{2} \mathrm{O}_{2}$ and is considered as a proof of concept for the approach. Targets of Trx, such as phosphoribulokinase, glyceraldehyde-3-phosphate dehydrogenase, transketolase, and sedoheptulose-1,7-bisphosphatase have at least one regulatory disulfide bridge which supports the conclusion that the identified proteins undergo reversible thiol oxidation. In conclusion, the presented approach enabled the identification of early targets of $\mathrm{H}_{2} \mathrm{O}_{2}$ oxidation within the cellular proteome under physiological experimental conditions.

Keywords: chloroplast proteome, hydrogen peroxide, methyl viologen, ribulose-bisphosphate carboxylase, redox regulation

\section{INTRODUCTION}

Chloroplasts are essential organelles in plant cells with a wide range of metabolic functions. The redox cascades of the lightdriven photosynthetic electron transport chain provide the driving force for metabolism, but they also conditionally generate oxidizing power in the form of reactive oxygen species (ROS). ROS levels increase due to several environmental factors influencing the photosynthetic efficiency, which in turn changes the redox state of the plastid (Foyer and Noctor, 2003). The redox state is also instrumental in regulating the chloroplast metabolic activities but also plastid and nuclear gene expression (Allen, 2003; Pfannschmidt, 2003; Pogson et al., 2008). Thus, chloroplasts serve as an excellent model for better understanding of the redox system

Abbreviations: Cys, cysteine; 2-Cys Prx, 2-cysteine peroxiredoxin; 2DE, twodimensional gel electrophoresis; DTNB, 5,5-dithio-bis(2-nitrobenzoic acid); DTT dithiothreitol; GAPDH, glyceraldehyde-3-phosphate dehydrogenase; HCF, high chlorophyll fluorescence; MALDI-TOF, matrix-assisted laser desorption/ionizationtime of flight; NEM, $\mathrm{N}$-ethylmaleimide; ROS, reactive oxygen species; RubisCO, ribulose-1,5-bisphosphate carboxylase/oxygenase; TCA, trichloroacetic acid. which enhances the plant tolerance to environmental stresses. Because of their central role in plant cell signaling, chloroplasts are also considered to function as sensors of environmental fluctuations. According to this scenario, the redox status of chloroplasts is crucial in biological stress response and helps the plant to cope with environmental changes (Scheibe and Dietz, 2012).

Cysteine (Cys) residues in proteins harbor thiol side chains that are highly reactive toward oxidants and can undergo various redox-based modifications. The oxidation of sensitive Cys may cause intra- or intermolecular disulfides. The concomitant conformational changes often regulate the activity and protect the critical thiols against irreversible oxidation (Brandes et al., 2009; König etal., 2012). Reactive thiols can form higher oxidation states like sulfenic acid $(\mathrm{SOH})$ and sulfinic acid $\left(\mathrm{SO}_{2} \mathrm{H}\right)$, which are reversed by thiol-specific cellular reductants like glutathione, thioredoxin, or sulfiredoxin (Liu et al., 2006). Hyperoxidation describes two forms of Cys oxidation, namely the $\mathrm{SO}_{2} \mathrm{H}$ and sulfonic acid $\left(\mathrm{SO}_{3} \mathrm{H}\right)$ states, the latter one being irreversible to our present-day knowledge. Cys can also form mixed-disulfides 
with glutathione (glutathionylation) or is S-nitrosylated. Both modifications receive increasing attention as important redox regulatory mechanism in biology (Mieyal and Chock, 2012). Through these different post-translational modifications Cys appears to be involved in virtually all cellular activities, including immediate metabolic regulation and control of transcriptional and translational activities in development and defense.

Analytical methods have been developed to detect reversible thiol oxidation and they employ combinations of labeling and blocking strategies. The challenge is to identify a few oxidized disulfides among the mass of reduced thiols of a healthy cell. Generally this method includes a saturating blockage of free thiols with thiol reactive reagents, followed by reduction of the disulfides (Muthuramalingam et al., 2010). Subsequently, the newly exposed thiol groups from the reduction step are labeled with detectable thiol-specific reagents. Depending on the specificity of the thiol reductant, this method can be used to identify all reversible thiol modifications (Leichert and Jakob, 2004). Novel labeling techniques based on isotope-coded affinity tags (ICAT) enable quantification of differential protein expression (Sethuraman et al., 2004). The combination of labeling strategies and advanced proteomic methodologies led to the identification of redox proteins which are regulated by thiol-disulfide transitions (Motohashi etal., 2001; Buchanan and Balmer, 2005; Rouhier et al., 2005; Bartsch et al., 2008; Ströher and Dietz, 2008). Often these studies employ rather extreme oxidizing condition. Thus a major open issue concerns the question as to which of the redoxregulated proteins are the primary targets of oxidation and how an initial redox imbalance is sensed in the cells.

Hydrogen peroxide $\left(\mathrm{H}_{2} \mathrm{O}_{2}\right)$ is a by-product of normal metabolism and has a sufficient half-life to allow its spreading throughout the entire cell (Bhattachrjee, 2005). $\mathrm{H}_{2} \mathrm{O}_{2}$ is involved in a number of signaling cascades (Neill et al., 2002) and also in programmed cell death in plants (Levine et al., 1994). A recent study has shown that aquaporins facilitate the movement of $\mathrm{H}_{2} \mathrm{O}_{2}$ across the membrane (Bienert et al., 2007). As thiols play major roles in ROS-mediated signaling pathways, identification of thiols that are most sensitive to $\mathrm{H}_{2} \mathrm{O}_{2}$ will help to understand the redoxsignaling pathways. Several proteomics studies have addressed the effects of $\mathrm{H}_{2} \mathrm{O}_{2}$ treatment of seedlings, roots and shoot on proteome composition and carbonylation state of proteins (Tanou et al., 2010; Barba-Espín et al., 2011; Zhou et al., 2011). These studies provide important insight into non-redox effects of $\mathrm{H}_{2} \mathrm{O}_{2}$ stress and downstream events of $\mathrm{H}_{2} \mathrm{O}_{2}$-dependent signaling in plants.

In this context, the present study focuses on the identification of chloroplast stroma proteins which are most sensitive to $\mathrm{H}_{2} \mathrm{O}_{2}$. Arabidopsis thaliana stroma proteins were subjected to partial oxidation by exogenous addition of limited amounts of $\mathrm{H}_{2} \mathrm{O}_{2}$ in order to observe the global response of the chloroplast redox network to an oxidizing stimulus. Initial targets of oxidation were identified by mass spectrometry (MS). In order to confirm the response of identified proteins to oxidation in vivo, plants were subjected to methyl viologen (MV) treatment. $\mathrm{MV}$ is a redox-active herbicide that accepts electrons at the photosystem I site and produces superoxide through reduction of oxygen within the chloroplasts (Halliwell and Gutteridge, 1989; Jacob and Dietz, 2009). The approach was successfully established and a first list of ROS-sensitive stroma proteins could be provided. Surprisingly, ribulose-1,5bisphosphate carboxylase oxygenase (RubisCO) proved to be a prominent target in vitro and in vivo, allowing us to hypothesize on its redox-buffering function during episodes of transient oxidative stress.

\section{MATERIALS AND METHODS GROWTH OF ARABIDOPSIS THALIANA AND CHLOROPLAST ISOLATION}

Arabidopsis thaliana (ecotype Columbia) was grown in soil culture with $10 \mathrm{~h}$ light $/ 14 \mathrm{~h}$ darkness at $22 / 18^{\circ} \mathrm{C}$, respectively, and a photosynthetic photon fluence rate of $120 \mu$ mol quanta $\mathrm{m}^{-2} \mathrm{~s}^{-1} .6$ week old plants were used for the chloroplast isolation. Leaves were harvested and homogenized in buffer containing $0.3 \mathrm{M}$ sorbitol, $20 \mathrm{mM}$ Tricine/KOH ( $\mathrm{pH}$ 8.4), $5 \mathrm{mM}$ ethylenediaminetetraacetic acid (EDTA) and $2 \mathrm{mM}$ ascorbic acid. The homogenate was filtered through eight layers of muslin cloth and nylon mesh. The debris was removed by centrifugation at $3000 \mathrm{rpm}$ and $4^{\circ} \mathrm{C}$ for $2 \mathrm{~min}$. The sedimented chloroplasts were resuspended in isolation buffer, containing $0.33 \mathrm{M}$ sorbitol, $5 \mathrm{mM} \mathrm{MgCl}_{2}, 20 \mathrm{mM}$ HEPES/KOH (pH 7.9), 2 mM EDTA with freshly added ascorbate. The resuspended chloroplasts were loaded on top of a Percoll step gradient consisting of layers with 40 and $80 \%$ Percoll medium containing $0.02 \mathrm{~g}$ Ficoll and $0.1 \mathrm{~g}$ PEG. The gradient was centrifuged at $3000 \mathrm{rpm}$ for $30 \mathrm{~min}$ without brakes. Intact chloroplasts were collected from the interphase between the Percoll layers and washed twice by spinning at $3000 \mathrm{rpm}$ for $2 \mathrm{~min}$. The stroma proteins were extracted following lysis and RubisCO was partially removed according to Ströher and Dietz (2008). The purity of stromal protein preparation was verified by using organelle specific enzymatic and antibody assay (Figure 1). The cytosolic marker enzyme UDP-glucose pyrophosphorylase (UGPase) activity was measured according to Zrenner et al. (1993). Using UDP-glucose and pyrophosphate as substrates, Glc-1-P released by UGPase was converted to glucose-6-phosphate (Glc-6-P) which was quantified by coupling to $\mathrm{NADP}^{+}$reduction by Glc-6-P dehydrogenase. Mitochondrial type II peroxiredoxin F (AtPrxIIF) was used as a marker for mitochondrial contaminations. Equal amounts of total plant and stromal proteins $(25 \mu \mathrm{g})$ were loaded and separated on reducing SDS-PAGE gels. Western blot analysis with antibodies raised against heterologous expressed AtPrxII F was performed as described in Finkemeier et al. (2005).

\section{DTNB-BASED OUANTIFICATION OF THIOL GROUPS}

Total sulfhydryl contents of stroma proteins were determined as described by Tietze (1969). Proteins were precipitated in 3\% trichloroacetic acid (TCA) and recovered after a brief centrifugation. To expose buried thiol groups the resulting pellet was dissolved in denaturing buffer containing $100 \mathrm{mM}$ Tris- $\mathrm{HCl}(\mathrm{pH}$ 8.0), $6 \mathrm{M}$ guanidinium $\mathrm{HCl}$ or $1 \%$ SDS. The free thiol groups were quantified spectrophotometrically at $412 \mathrm{~nm}$ using $6 \mathrm{mM}$ 5,5-dithio-bis(2-nitrobenzoic acid; DTNB) as substrate.

\section{SAMPLE PREPARATION (IN VITRO AND IN VIVO OXIDATION TREATMENT)}

Partial oxidation in vitro was performed in $20 \mathrm{mM}$ Tris- $\mathrm{HCl}(\mathrm{pH}$ 7.8) buffer by adding $\mathrm{H}_{2} \mathrm{O}_{2}$ in varying stoichiometric quantities equivalent to $1,2.5,5$, and $10 \%$ of the protein thiol content 


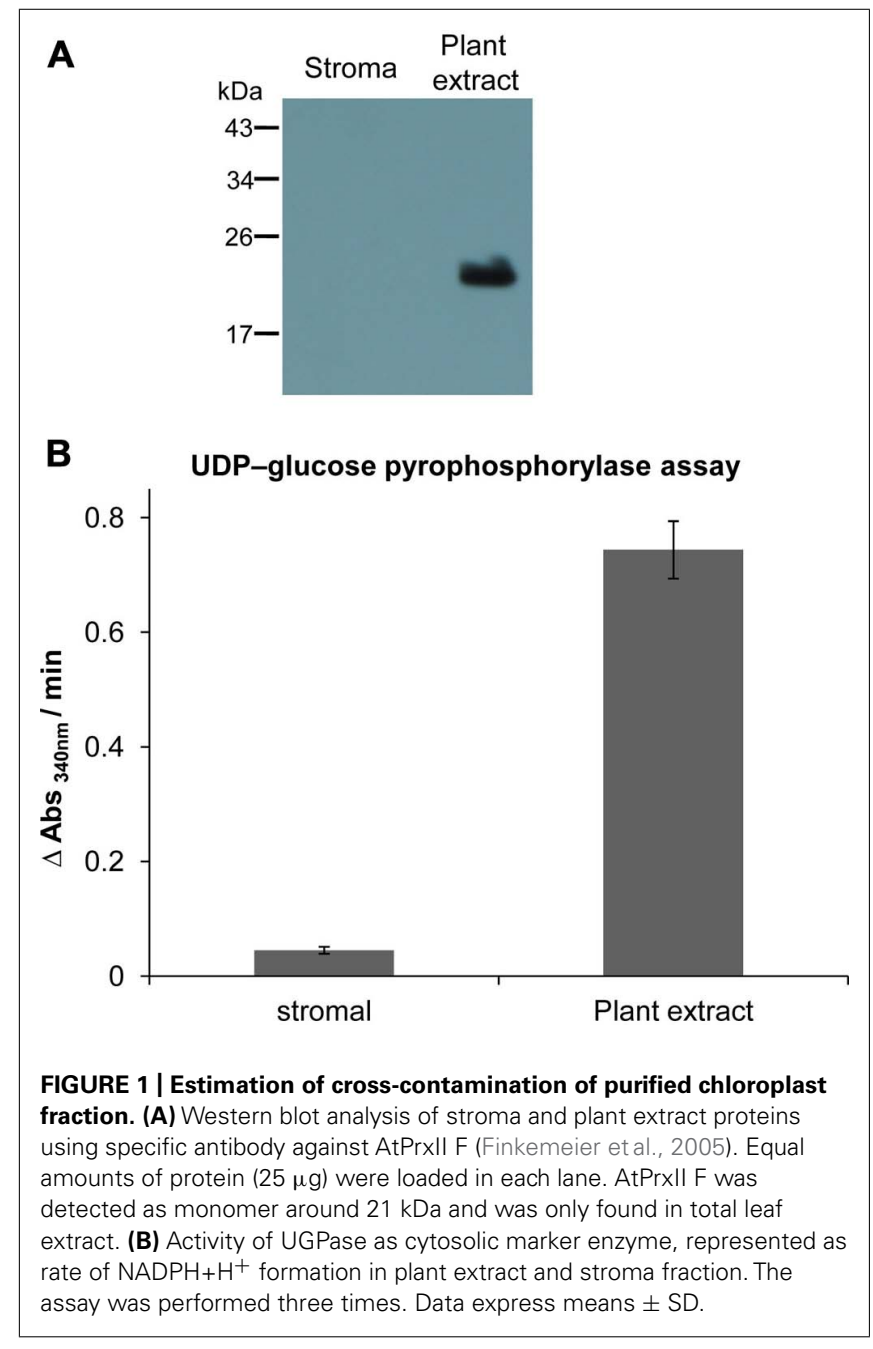

determined by DTNB assay in the respective fraction. The range of ratios which was usually equivalent to $1-10 \mu \mathrm{M}$ concentrations was selected to identify preferred sites for oxidation. For in vivo oxidation, $50 \mu \mathrm{M}$ MV supplemented with $0.1 \%$ Tween20 was sprayed on whole plants that were harvested after 10 , 30 and $60 \mathrm{~min}$. Three independent experiments were performed for both in vitro and in vivo oxidation treatments and the identified target proteins are representative of respective replicate experiments.

\section{DETECTION OF REDOX-REGULATED PROTEINS VIA A SEQUENTIAL LABELING STRATEGY}

All buffers were depleted from dissolved $\mathrm{O}_{2}$ by bubbling with argon gas at room temperature (RT). The stroma protein fraction was completely reduced in the presence of $25 \mathrm{mM}$ dithiothreitol (DTT). The reaction was performed inside a closed microaerobiosis chamber continuously flushed with nitrogen gas produced in a nitrogen generator to maintain the oxygen content at less than $0.4 \%$. Excess DTT was removed by desalting using $10 \mathrm{ml}$ desalting columns. The proteins in $20 \mathrm{mM}$ Tris- $\mathrm{HCl}(\mathrm{pH} 7.8)$ buffer with about $100 \mu \mathrm{M}$ thiols were treated with $\mathrm{H}_{2} \mathrm{O}_{2}$ (about $10 \mu \mathrm{M}$ ) for 5 min with gentle shaking to identify the initial targets of oxidation. Remaining cysteinyl thiols were alkylated using $100 \mathrm{mM}$ $N$-ethylmaleimide (NEM) in darkness for $1 \mathrm{~h}$ to prevent oxidation. Excess NEM was removed by TCA precipitation according to Muthuramalingam et al. (2010). The washed precipitate was solubilized in denaturing buffer containing $200 \mathrm{mM}$ Bis-Tris ( $\mathrm{pH} 6.5$ ), $6 \mathrm{M}$ urea, $0.5 \%(\mathrm{w} / \mathrm{v})$ SDS and $10 \mathrm{mM}$ EDTA supplemented with $100 \mathrm{mM}$ DTT to allow full reduction of oxidized thiols. Excess DTT was removed by repeated TCA precipitation. The labeling of the rereduced, previously oxidized thiols was achieved with $25 \mathrm{mM}$ biotin maleimide in the dark for 90 min under constant shaking. Excess labeling reagent was removed either by TCA precipitation or with PD-10 desalting columns (GE Healthcare) depending on the downstream processing.

To monitor the in vivo redox status of proteins, proteins from MV-treated plants were extracted in the presence of $100 \mathrm{mM}$ NEM. Furtheron, the proteins were reduced with DTT and subsequently labeled with biotin maleimide as described above. Biotinylated proteins were separated either by one or two-dimensional gel electrophoresis (2DE) and subsequently transferred onto nitrocellulose membrane using the semidry blotter Fastblot B44 (Whatman/Biometra, Germany). After a blocking step with $1 \%$ fish gelatin (Sigma, Germany) for $2 \mathrm{~h}$ at RT, the membrane was probed with anti-biotin antibody (Clone BN-34 from Sigma-Aldrich, St. Louis, USA). Then the membrane was incubated for $1 \mathrm{~h}$ with horseradish peroxidase-conjugated anti-mouse antibody (SigmaAldrich, St. Louis, USA) and developed using the enhanced chemiluminescence method (Thermo Scientific, Germany).

\section{STREPTAVIDIN AFFINITY PURIFICATION}

The protein samples were desalted to remove labeling solution. This was needed since denaturing reagents used for solubilizing TCA-precipitated protein pellets inhibited binding of biotinylated polypeptides to the streptavidin column. Biotinylated proteins were enriched using streptavidin agarose. The biotinylated sample was incubated with streptavidin agarose equilibrated with phosphate buffered saline (PBS) buffer, $\mathrm{pH} 7.4$, at $4^{\circ} \mathrm{C}$ with constant shaking overnight. Nonspecifically bound proteins were washed with $1 \times$ PBS until the absorbance at $280 \mathrm{~nm}$ reached zero. Proteins were incubated with elution buffer containing $1 \%$ SDS, $30 \mathrm{mM}$ biotin ( $\mathrm{pH} \mathrm{12}$ ) for $15 \mathrm{~min}$ at RT, followed by heating at $96^{\circ} \mathrm{C}$ for 15 min.

\section{IDENTIFICATION OF PROTEINS USING MALDI MS ANALYSIS}

Proteins purified by streptavidin agarose were resolved by onedimensional SDS-PAGE and stained with silver nitrate according to Blum et al. (1987). Spots of interest were excised from the gel and placed in U-shaped microtiter plate wells (Greiner Bio-one, Germany). To remove the silver, the excised gel spots were de-stained using Farmer's reducing reagent containing $30 \mathrm{mM}$ potassium ferricyanide (III) and $100 \mathrm{mM}$ sodium thiosulfate. Then the gel spots were washed several times with ultrapure $\mathrm{H}_{2} \mathrm{O}$ until the gel slices became transparent. Protein spots were washed twice with $30 \%(\mathrm{v} / \mathrm{v})$ acetonitrile in $0.1 \mathrm{M}$ ammonium hydrogen carbonate and subsequently dried in the speedvac. The gel pieces were rehydrated in the presence of $0.01 \mu \mathrm{g}$ trypsin/ $\mu \mathrm{l}$ (Promega, Mannheim, Germany) at RT for $30 \mathrm{~min}$ followed by overnight incubation at $37^{\circ} \mathrm{C}$ according to manufacturer's protocol. The gel 
slices were vacuum dried, and the peptides were extracted with $50 \%$ acetonitrile and $0.1 \%$ trifluoroacetic acid for MS analysis. Acquisition of peptide mass fingerprint data and corresponding LIFT spectra was performed using an ultrafleXtreme matrixassisted laser desorption/ionization time-of-flight (MALDI-TOF) device (Bruker Daltonics, Bremen, Germany) equipped with a Smartbeam-II laser with a repetition rate of $1000 \mathrm{~Hz}$. The spectra were calibrated using external calibration and subsequent internal mass correction. For databank searching, Biotools 3.2 software (Bruker Daltonics) with the implemented MASCOT search engine (Matrix Science) was used, searching for A. thaliana in the non-redundant National Center for Biotechnology Information database (26/07/2010, 55602 sequences). Search parameters were as follows: monoisotopic mass accuracy; 50 ppm tolerance; fragment tolerance of $0.3 \mathrm{Da}$; missed cleavages 1 ; and the allowed variable modifications were oxidation (Met), propionamide (Cys), and carbamidomethyl (Cys). Proteins were identified from all three independent experiments applying MASCOT significance scores of 60 (protein level) and 32 (peptide level). Proteins found in just one of the experiments are indicated in table legends (Tables 1-3).

\section{BIOTIN QUANTIFICATION ASSAY}

The extent of biotinylation was quantified using the HABA-avidin assay developed by Green (1975). HABA forms a red complex with avidin that can be monitored spectrophotometrically at $500 \mathrm{~nm}$. Due to its higher affinity, biotin displaces HABA, accompanied by the decrease in absorbance at $500 \mathrm{~nm}$. The biotinylated protein samples were desalted to remove the excess of biotin maleimide reagent before performing the assay. The assay mixture consisted of $1 \times$ PBS buffer containing HABA-avidin reagent (Sigma, Germany) and $10 \mu \mathrm{g}$ of biotinylated protein sample. After $2 \mathrm{~min}$ incubation the absorbance at $500 \mathrm{~nm}$ was recorded. The change in absorbance at $500 \mathrm{~nm}$ is proportional to the amount of biotin in the assay. A standard curve was generated using free biotin and used to estimate the number of moles of biotin incorporated after biotinylating the protein.

\section{RESULTS \\ PURITY OF THE CHLOROPLAST FRACTION}

Chloroplasts were isolated and lysed to obtain a stromal protein fraction which was checked for contaminations by other cellular constituents. Type II peroxiredoxin F (AtPrxII F) was used as a marker for mitochondrial contamination using Western blot analysis. In total plant protein extract AtPrxII F was detected at the expected size of about $21 \mathrm{kDa}$, while it was absent in the stromal fraction (Figure 1A). As shown in Figure 1B the plant protein extract exhibited high rates of nicotinamide adenine dinucleotide phosphate (NADPH) formation at $340 \mathrm{~nm}$, representative for high UGPase activity, while its enzymatic activity in the stromal fraction was minimal with less than $6 \%$ relative contamination.

\section{TOTAL PROTEIN THIOL DETERMINATION}

The present study aimed to identify the primary protein targets of $\mathrm{H}_{2} \mathrm{O}_{2}$ oxidation in the chloroplast in vitro and in vivo. Percoll-purified intact chloroplasts were lysed, and the stroma

Table 1 | Arabidopsis thaliana stroma proteins containing $\mathrm{H}_{2} \mathrm{O}_{2}$ sensitive thiols identified by MALDI-TOF/MS.

\begin{tabular}{|c|c|c|c|c|c|}
\hline No. & Protein & Accession number & MM (kDa) & Cys number & Functional role \\
\hline 1 & Fd-GOGAT & AT5G04140 & 165.3 & 24 & Nitrogen assimilation \\
\hline 2 & Transketolase & AT3G60750 & 73.1 & 8 & Photosynthesis \\
\hline 3 & RubisCO large subunit & ATCG00490 & 52.9 & 9 & Photosynthesis \\
\hline 4 & Fructose-bisphosphate aldolase-2 & AT4G38970 & 37.9 & 2 & Photosynthesis \\
\hline 5 & GAPDH subunit B & AT1G42970 & 39.3 & 7 & Photosynthesis \\
\hline 6 & GAPDH subunit A-2 & AT1G12900 & 37.7 & 5 & Photosynthesis \\
\hline 7 & Ferredoxin-NADP $(+)$ oxidoreductase 1 & AT5G66190 & 35.2 & 5 & Photosynthesis \\
\hline 8 & Carbonic anhydrase 1 & AT3G01500 & 25.6 & 6 & Photosynthesis \\
\hline 9 & 2-Cys peroxiredoxin & AT3G11630 & 22.4 & 2 & Detoxification \\
\hline 10 & Cyclophilin 20-3 & AT3G62030 & 19.9 & 4 & Protein folding \\
\hline 11 & RubisCO small subunit & AT1G67090 & 14.7 & 4 & Photosynthesis \\
\hline $12^{*}$ & Phosphoribulokinase & AT1G32060 & 39.2 & 4 & Photosynthesis \\
\hline $13^{*}$ & STN7 kinase & AT1G68830 & 58.5 & 5 & Serine/threonine kinase \\
\hline $14^{*}$ & Glutamine synthetase 2 & AT5G35630 & 42.5 & 6 & Ammonia assimilation cycle \\
\hline $15^{*}$ & ATP synthase beta subunit & ATCG00480 & 52.5 & 1 & ATP synthesis \\
\hline $16^{*}$ & HCF 136 & AT5G23120 & 35.8 & 0 & PSII stability complex \\
\hline $17^{*}$ & DRT 112 & AT1G20340 & 10.5 & 1 & Electron carrier \\
\hline
\end{tabular}

Each protein is annotated by its name, accession number, molecular weight (without predicted transit peptide), and the biological function. The number of cysteines theoretically present in the mature protein is given. The table compiles the results from three independent experiments. Proteins 1-11 were identified in each experiment. Asterisk "*" denotes that these proteins were identified in single experiments where $10 \%$ molar equivalence to protein thiols corresponded to $15 \mu \mathrm{M}$ $\mathrm{H}_{2} \mathrm{O}_{2}$ concentration 
Table 2 | Identification of cysteines modified upon oxidation.

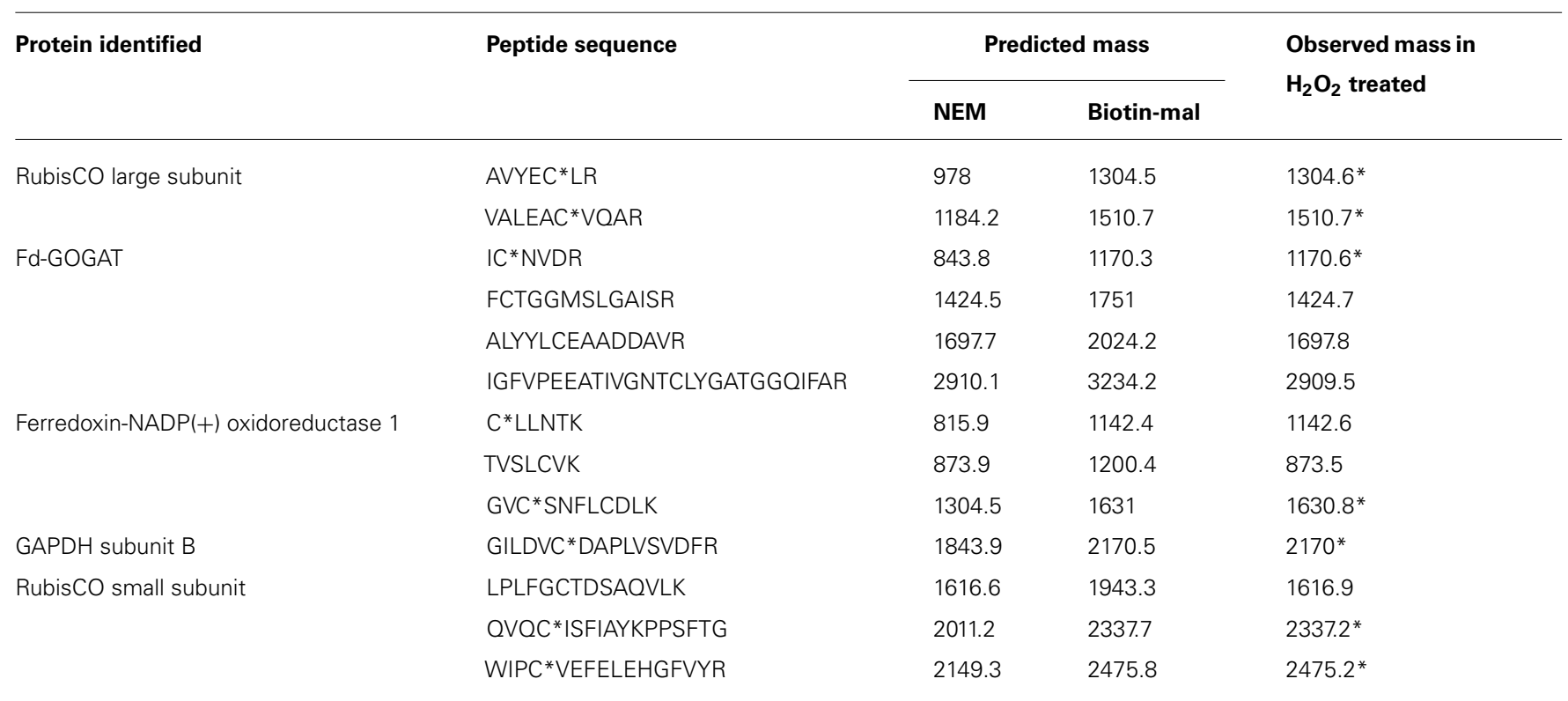

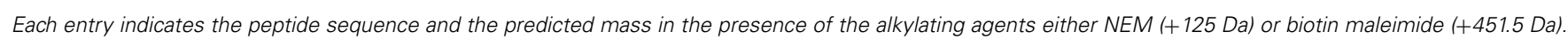

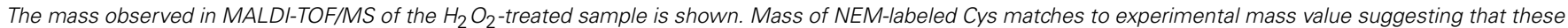

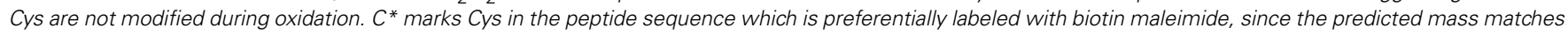

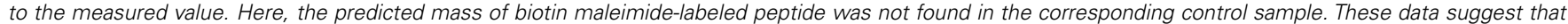
the approach used can identify proteins sensitive to oxidation and in addition locates the Cys modification.

protein fraction was recovered by centrifugation. Total thiol contents of stroma protein extract was determined using the DTNB assay in order to adjust the amount of $\mathrm{H}_{2} \mathrm{O}_{2}$ to be added for oxidation to $10 \%$ of total protein thiols. Protein thiols were quantified under reducing and denaturing conditions to obtain an average amount of thiols to be used as a conversion factor for future experiments. Low molecular weight thiol metabolites such as glutathione were removed by TCA precipitation, followed by a centrifugation. Both denaturing methods, namely guanidinium hydrochloride- and SDS-treatment gave a highly similar result of $57.1 \pm 4.3$ and $58.3 \pm 3.1 \mu \mathrm{mol} / \mathrm{g}$ protein, respectively (mean $\pm \mathrm{SD}$ of $n=3$ ), corresponding to an average of 3 Cys per $50 \mathrm{kDa}$ protein.

In order to optimize the workflow (Figure 2A) and to check for reaction specificity, 2-cysteine peroxiredoxin (2-Cys Prx) was used as test protein, since it is a well characterized redox-regulated protein (Figure 2B). 2-Cys Prx has two cysteinyl residues and forms an intermolecular disulfide bond upon oxidation. Thus the oxidized form runs as a dimer on non-reducing SDS-PAGE. To check the specificity of the labeling strategy, proteins were directly labeled with biotin maleimide after each step of the work flow and detected immunologically with antibody against biotin. As shown in Figure 2B, free thiols were not available for biotin maleimide labeling after oxidation of 2-Cys Prx as indicated by the absence of signal in the Western blot (lane 2). A similar result was observed after blocking of free thiols with NEM, an alkylating agent to prevent thiol-disulfide exchange reactions (lane 3). After reduction, Cys were efficiently labeled with biotin maleimide and strong bands were detected in the blot (lane 1 and 4 ). The band detected around $48 \mathrm{kDa}$ corresponds to the half-oxidized dimer, since each dimer contains two catalytic sites each of which can form a disulfide bridge.

\section{EFFECT OF $\mathrm{H}_{2} \mathrm{O}_{2}$-MEDIATED OXIDATION ON STROMA THIOL PROTEINS}

Stroma proteins were subjected to $\mathrm{H}_{2} \mathrm{O}_{2}$ oxidation, subsequently reduced and labeled with biotin maleimide. Oxidation was performed by adding $\mathrm{H}_{2} \mathrm{O}_{2}$ at amounts of varying stoichiometry relative to protein thiol contents $(1,2.5,5$, and $10 \%)$ which corresponded to 1 to $10 \mu \mathrm{M}$ concentration. Under optimal conditions for photosynthesis, $\mathrm{H}_{2} \mathrm{O}_{2}$ concentrations are considered to be below $1 \mu \mathrm{M}$. $\mathrm{H}_{2} \mathrm{O}_{2}$ accumulates under stress. $10 \mu \mathrm{M} \mathrm{H}_{2} \mathrm{O}_{2}$ inhibits the Calvin cycle in isolated chloroplast by half (Kaiser, 1976; Asada, 1999; Polle, 2001). Remaining free thiols were blocked with NEM followed by reduction of reversibly oxidized proteins with DTT. The newly recovered thiol groups were then labeled with biotin maleimide. Hence biotinylated proteins corresponded to Cys-containing proteins that had been reversibly oxidized by the added $\mathrm{H}_{2} \mathrm{O}_{2}$. The increase in biotin label corresponding to increased oxidation is shown in Figure 3A. In the control reaction, the proteins were reduced and directly blocked with NEM without exposure to $\mathrm{H}_{2} \mathrm{O}_{2}$. Complete reduction and immediate blocking of free thiols in the control sample resulted in only minor incorporation of biotin maleimide into proteins (Figure 3A; lane 1). The labeling degree increased with increasing $\mathrm{H}_{2} \mathrm{O}_{2}$ concentrations.

The amount of biotin maleimide in the labeled samples was quantified with the HABA-avidin assay. Equal amounts of protein from different $\mathrm{H}_{2} \mathrm{O}_{2}$-treated and control samples were mixed with HABA-avidin reagent. The assay displayed a decrease in the absorbance that is proportional to the amount of biotin maleimide present in the sample. The degree of biotinylation was calculated as 
Table 3 | Oxidation-susceptible proteins in A. thaliana treated with methyl viologen, subjected to differential labeling and identified by MS.

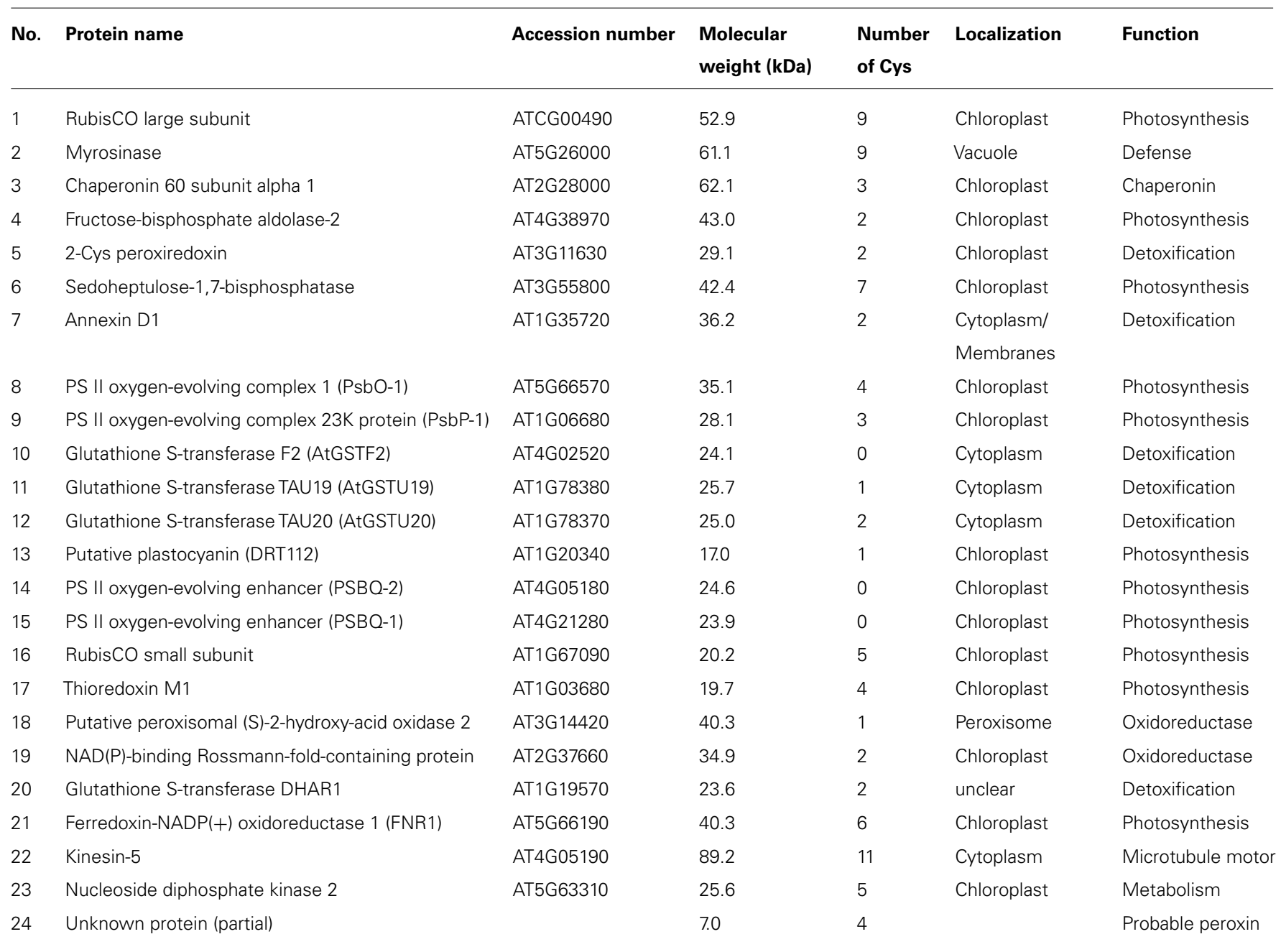

Each protein is annotated by its name, accession number, molecular weight, subcellular localization, and biological function as given in the plant protein database $(P P D B)$. The number of cysteines theoretically present in the mature protein is given. The table compiles the results from three independent experiments. Proteins 3 , $7,10,12,18,20,22,23$, and 24 were significantly identified in one experiment only.

micromol biotin-labeled thiol per gram protein. As expected the increasing amounts of $\mathrm{H}_{2} \mathrm{O}_{2}$ and subsequent reduction allowed the incorporation of more biotin, representing the extent of thiol oxidation (Figure 3B).

Two-dimensional gel electrophoresis was performed in order to get insight into the complexity of the $\mathrm{H}_{2} \mathrm{O}_{2}$-mediated oxidative changes. One hundred micrograms of biotin maleimide-labeled control and $\mathrm{H}_{2} \mathrm{O}_{2}$-treated proteins were separated by 2DE and subsequently visualized by silver staining (Figure 4A). The corresponding Western blot membranes probed with anti-biotin antibody are shown in Figure 4B. The patterns of biotinylated polypeptides differed strongly between control and treated samples, while the patterns from the silver-stained gel detecting total proteins revealed a similar spot pattern despite the fact that apparently slightly more protein had been solubilized in the $\mathrm{H}_{2} \mathrm{O}_{2}$-treated sample. The direct comparison of the blots and the silver-stained gels for identifying and excising the proteins of interest appeared unreliable due to the expected background of unlabeled polypeptides. Therefore the biotinylated proteins were further enriched by purification via streptavidin agarose column chromatography.

\section{PURIFICATION AND IDENTIFICATION OF BIOTINYLATED PROTEINS FOLLOWING $\mathrm{H}_{2} \mathrm{O}_{2}$-MEDIATED OXIDATION}

Biotin-labeled control and $\mathrm{H}_{2} \mathrm{O}_{2}$-treated samples were purified by streptavidin agarose chromatography to separate the $\mathrm{H}_{2} \mathrm{O}_{2}$ sensitive biotinylated proteins from the complex protein mixture. Affinity-purified proteins were precipitated with TCA $(10 \% \mathrm{w} / \mathrm{v})$ to remove excess biotin from elution. The protein samples were resolved by one-dimensional SDS-PAGE analysis and visualized by silver staining (Figure 5A). Both control and $\mathrm{H}_{2} \mathrm{O}_{2}$-treated proteins exhibited a similar pattern on the gel, which is explained by loading equal protein amounts. However, immuno-reactive signals only appeared on the blot from $\mathrm{H}_{2} \mathrm{O}_{2}$-treated samples, confirming that the biotin labeling was linked to protein oxidation by $\mathrm{H}_{2} \mathrm{O}_{2}$ (Figure 5B). To identify proteins containing redox sensitive Cys thiols the indicated gel sections were excised from the gel. Results of MALDI-TOF/MS analysis are summarized in 


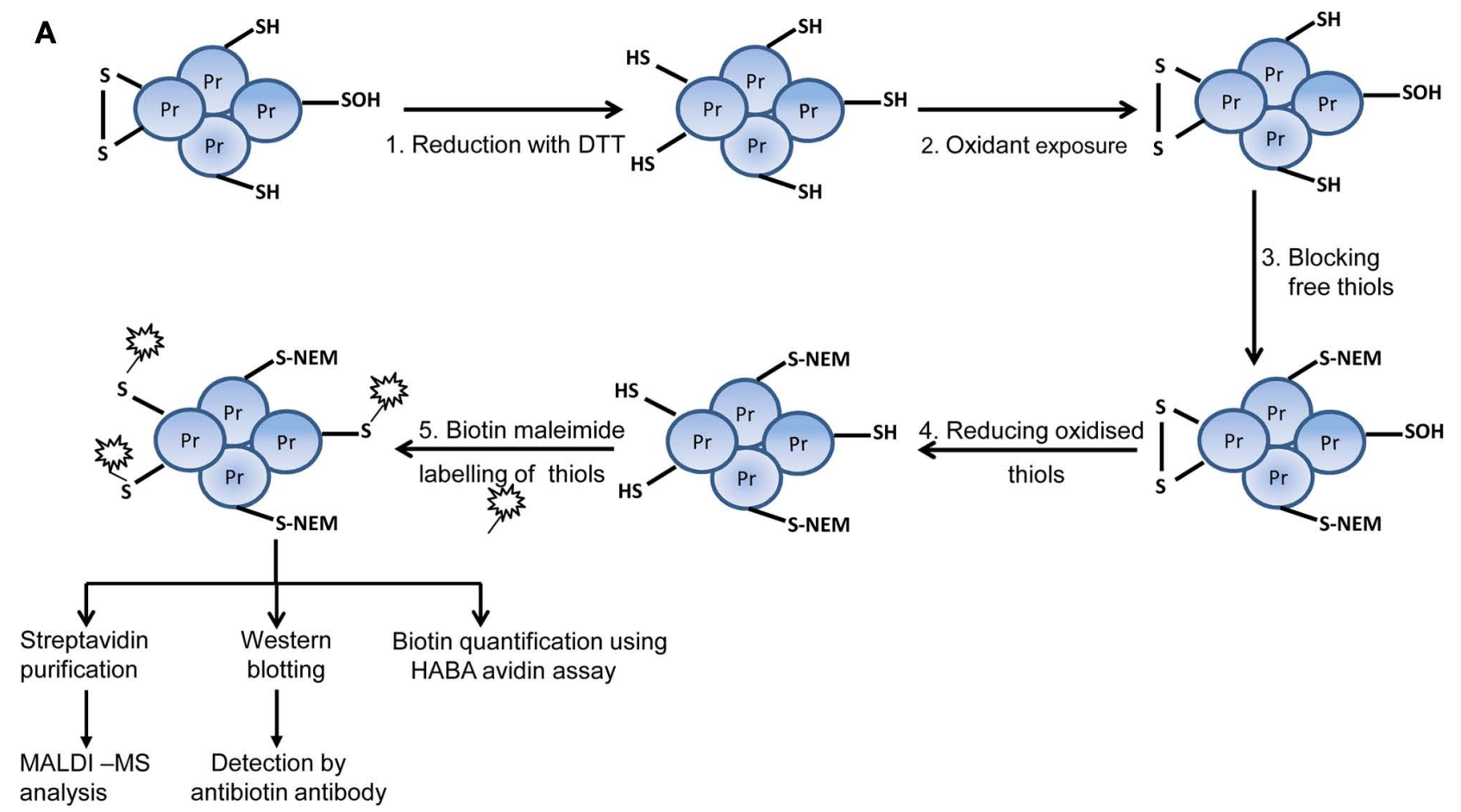

B

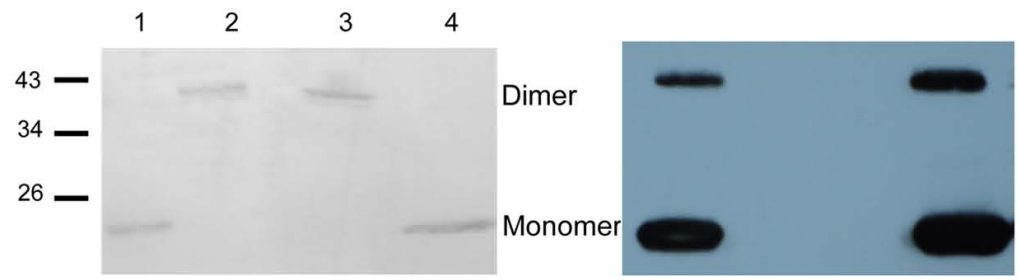

FIGURE 2 | Overview of the procedure for labeling reversibly oxidized cysteines and test experiment with 2-Cys Prx. (A) Work flow used for identifying protein targets sensitive to low $\mathrm{H}_{2} \mathrm{O}_{2}$ concentrations consisted of five steps: step 1 includes complete reduction of protein thiols using the artificial reductant DTT. Step 2: After desalting to remove excess DTT, proteins were exposed to $\mathrm{H}_{2} \mathrm{O}_{2}$ for 5 min. In step 3, free thiol groups were blocked using NEM under denaturing conditions. Reversibly oxidized thiols were reduced with DTT in step 4. The newly exposed thiol groups were labeled using the thiol specific reagent biotin maleimide in step 5. As a control reaction, proteins were not subjected to oxidation (step 2) while all other steps were done as described above. From steps 1 to 3 , the samples were treated inside the microaerobic chamber with $<0.4 \% \mathrm{O}_{2}$. Subsequent steps were performed in ambient air. (B) Test of experimental workflow with 2-Cys Prx. Each subunit of the 2-Cys Prx dimer has two cysteines. Biotin labeling of reduced 2-Cys Prx (lane 1); oxidized (lane 2); reduced and blocked with NEM (lane 3 ), and reduced, oxidized and re-reduced sample (lane 4). On the left is the Ponceau S-stained membrane which shows equal protein amounts loaded. The corresponding blot developed with antibody against biotin is shown on the right and is representative for three experiments.
Table 1. In total 17 proteins were identified from affinity purified $\mathrm{H}_{2} \mathrm{O}_{2}$-treated samples. All identified proteins are located to the chloroplast. Five proteins function in the Calvin cycle (protein \# 2, 5, 6, 11, and 12). The other identified proteins have various functions, such as nitrogen assimilation (proteins \#1 and 14), adenosine triphosphate (ATP) synthesis (protein \#15) and electron transport (protein \# 17) among others. The analysed amino acid composition of these proteins revealed that except for the photosystem II (PSII) stability/assembly factor HCF136 (protein \#16) one or more Cys are present in all identified proteins. To confirm oxidation-mediated Cys modification in $\mathrm{H}_{2} \mathrm{O}_{2}$-treated samples, the mass lists of unmatched peptides were compared with the predicted mass of in silico trypsin-digested and biotinylated peptides (Table 2). This approach allowed us to confirm two peptides of the large subunit (LSU) and small subunit (SSU) of RubisCO, single peptides of ferredoxin-dependent glutamate synthase (Fd-GOGAT), subunit B of GAPDH and ferredoxin-NADP oxidoreductase (FNR).

\section{PURIFICATION AND IDENTIFICATION OF BIOTINYLATED PROTEINS FOLLOWING MV-MEDIATED OXIDATION}

To determine whether and which proteins are oxidized in vivo, 6 week old plants were sprayed with MV that induces photooxidative stress. The MV treatment of plants revealed a slight increase in biotinylated proteins after different times (Figure 6A). Under oxidizing conditions the catalytic Cys of 2-Cys Prx form an intermolecular disulfide bridge, and it runs as dimer at about $43 \mathrm{kDa}$, whereas the fully reduced form runs as monomer of 


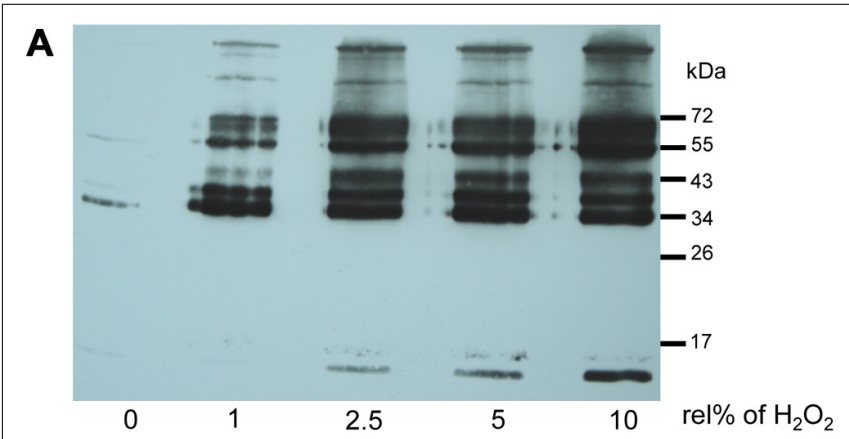

B

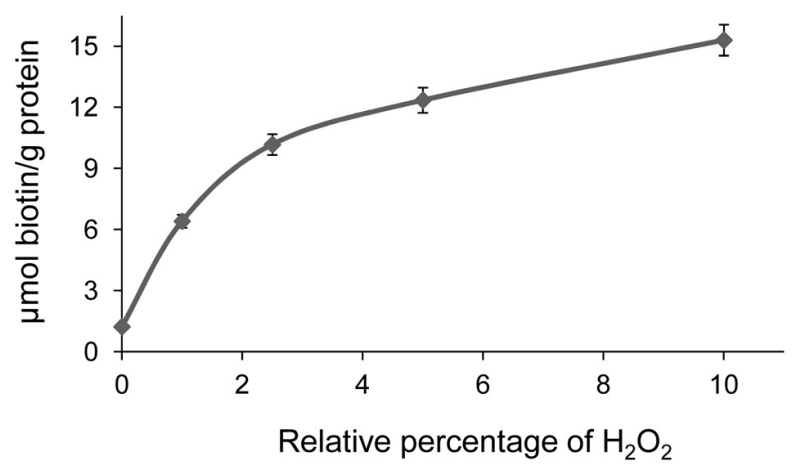

FIGURE 3 | $\mathrm{H}_{2} \mathrm{O}_{2}$-dependent oxidation of stroma proteins. (A) Western blot analysis with anti-biotin antibody to detect oxidized stroma proteins. "rel\%" stands for the amount of $\mathrm{H}_{2} \mathrm{O}_{2}$ added relative to the thiol contents of the protein sample $(100 \%)$. The bands demonstrate $\mathrm{H}_{2} \mathrm{O}_{2}$-dependent oxidation of stroma proteins. Same samples were used for biotin quantification. The experiment with similar results was performed three times. (B) Degree of biotinylation in $\mathrm{H}_{2} \mathrm{O}_{2}$-treated samples as calculated from HABA displacement assay. For biotin quantification, $10 \mu \mathrm{g}$ of proteins were used. Data are means $\pm S D, n=3$.

$22 \mathrm{kDa}$. At higher oxidant concentrations 2-Cys Prx is prone to overoxidation, which also results in a monomer (data not shown). After 30 min of MV treatment 2-Cys Prx was fully oxidized as shown in the immunoblot analysis (Figure 6B). At the later time points the protein was found as monomer again, suggesting overoxidation. Based on the redox behavior of one of the early target proteins, namely 2-Cys Prx, the 30-min exposure time was selected for further experiments.

After $30 \mathrm{~min}$ exposure to $\mathrm{MV}$, proteins were extracted in NEM-containing buffer. Extracted and alkylated proteins were reduced, free thiols labeled with biotin maleimide and subsequently purified via streptavidin column. After elution, the proteins were resolved by SDS-PAGE and identified using MS (Table 3). In total 24 proteins were repeatedly identified from affinity purified MV-treated samples. Most identified proteins are located to the chloroplast, while some are located to the cytoplasm (protein \#7,10,11,12, and 22), the vacuole (protein \#2), the peroxisome (protein \#18) and the mitochondrion (protein \# 20). Some target proteins such as RubisCO, myrosinase, and fructose-bisphosphate aldolase- 2 were found both in control and MV-treated plants. Proteins that were differentially oxidized by MV treatment are discussed below. Among these were
2-Cys Prx, sedoheptulose-1,7-bisphosphatase (SBPase), subunits of the water-oxidizing complex and FNR1. Six in vivo identified proteins were common with the in vitro $\mathrm{H}_{2} \mathrm{O}_{2}$-treated sample, namely RubisCO LSU and SSU, fructose-bisphosphate aldolase-2, 2-Cys Prx, plastocyanin (DRT 112) as well as FNR. Most identified chloroplast proteins function in photosynthesis (proteins \# 8, 9, 14, and 15) and redox homeostasis (proteins \# 5, 19, 20, 21, and 24), while others are involved in photorespiration (protein \#1), Calvin cycle (protein \#6 and 16) and electron transport (proteins \#13 and 17).

Except for the glutathione S-transferase (GST) F2 (protein \#10), PSBQ-2 (protein \#14), and PSBQ-1 (protein \#15), one or more Cys are theoretically present in all identified proteins when analyzing the amino acid composition. The oxidation-mediated Cys modifications in MV-treated samples were identified by comparing the predicted mass list of in silico trypsin-digested and biotinylated peptides (Table 4). This approach allowed us to confirm single peptides of RubisCO LSU, myrosinase, NAD(P)-binding Rossmann-fold-containing protein and FNR.

\section{DISCUSSION}

In order to identify stroma protein targets sensitive to oxidation by $\mathrm{H}_{2} \mathrm{O}_{2}$, this work adopted a strategy similar to the "biotin switch"-method used to detect post-translational $S$-nitrosylation or glutathionylation (Jaffrey and Snyder, 2001; Lind et al., 2002). The present study relies on differential labeling of reduced thiols and formerly oxidized thiols, using two different alkylation reagents (NEM and biotin maleimide) of distinct molecular mass, which eased the preferential identification of the $\mathrm{H}_{2} \mathrm{O}_{2}$-sensitive proteins. Often redox proteomic studies identify redox-sensitive proteins by direct labeling of proteins during cell extraction, possibly leading to Cys oxidation during the lysis and labeling steps causing false positive results. The cross contamination assays indicate that the isolated chloroplast fractions were highly pure since the mitochondrial protein AtPrxII F was below detection limit (Figure 1A) and the cytosolic UGPase constituted less than $6 \%$ on a protein basis (Figure 1B). In the in vitro part of this work, the stroma proteins were completely reduced and then oxidized with low amounts of $\mathrm{H}_{2} \mathrm{O}_{2}$ to isolate only the most oxidant-sensitive protein thiols. It has been suggested that about $4 \mu \mathrm{mol} \mathrm{H}_{2} \mathrm{O}_{2} \mathrm{~m}^{-2}$ leaf area ${ }^{-1}$ is formed in the chloroplast during photosynthesis under normal conditions (Foyer and Noctor, 2003). This value corresponds to about $300 \mu \mathrm{mol} \mathrm{H}_{2} \mathrm{O}_{2}$ $\mathrm{L}^{-1}$ stroma produced every second, assuming a leaf chlorophyll content of $300 \mathrm{mg}^{-2}$ and a stroma volume of $40 \mu \mathrm{L} \mathrm{mg} \mathrm{m}^{-1}$ chlorophyll. The $\mathrm{H}_{2} \mathrm{O}_{2}$-detoxification capacity of the chloroplast ascorbate- and peroxiredoxin-dependent water-water cycles is high, and models predict that resting $\mathrm{H}_{2} \mathrm{O}_{2}$ concentrations are low as long as reductants are available (Polle, 2001). Here a low $\mathrm{H}_{2} \mathrm{O}_{2}$ concentration of about $10 \mu \mathrm{M}$ equivalent to $10 \%$ of total protein thiols was used to identify primary targets of oxidation and can be considered to represent physiologically relevant conditions. In previous studies much higher concentrations of oxidants ranging from $1 \mathrm{mM}$ up to $10 \mathrm{mM}$ in non-stoichiometric amounts have been used in plant and animal redox proteomic studies. The results from such studies should be considered with care, since the employed concentrations are 


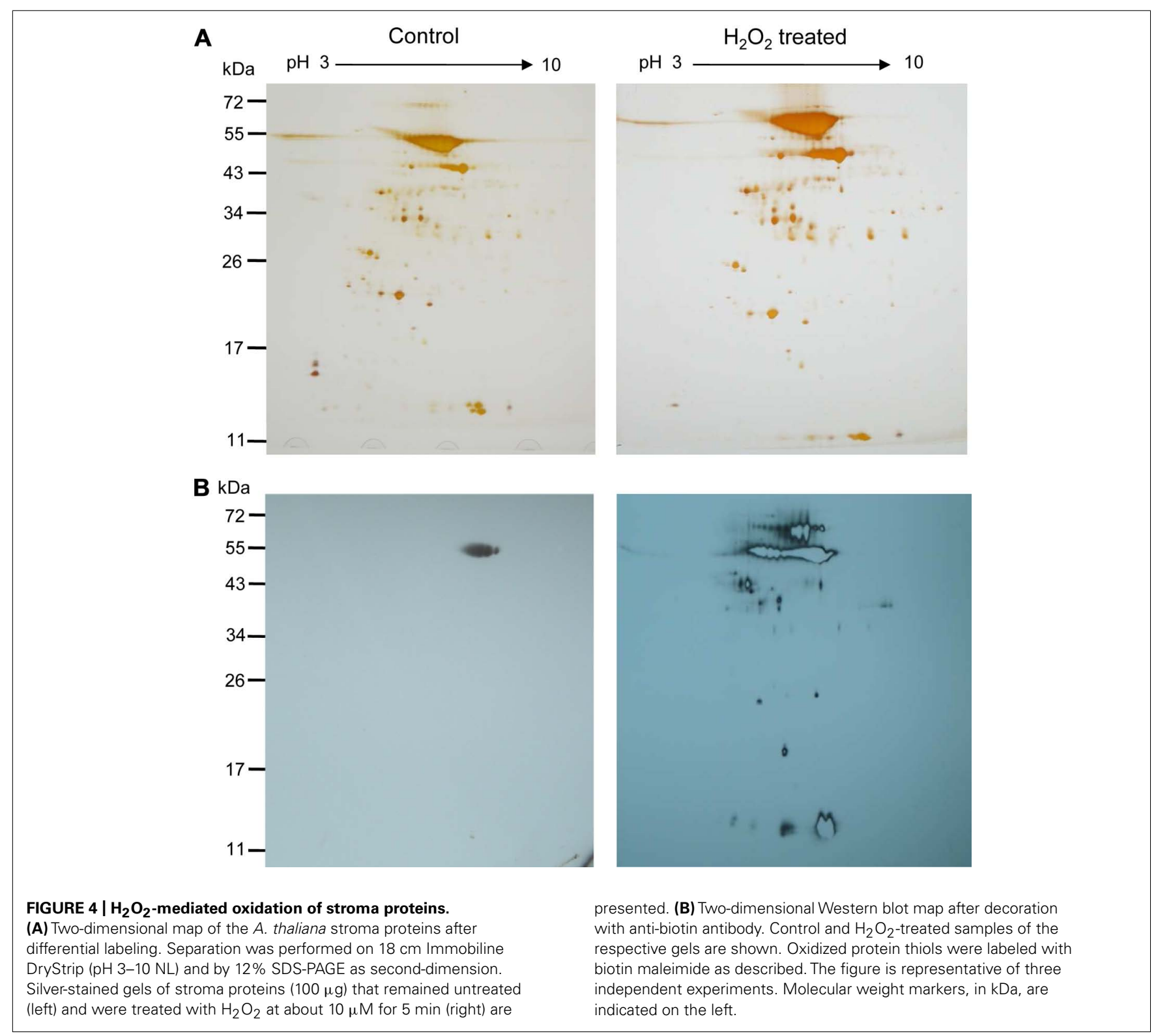

often outside the reasonable physiological range (Kim et al., 2000; Baty et al., 2002; Marx et al., 2003; Sethuraman et al., 2004; Winger et al., 2007).

The degree of labeling with biotin-maleimide increased in the $\mathrm{H}_{2} \mathrm{O}_{2}$-treated sample indicating the occurrence of oxidationmediated Cys modification in our experiments (Figure 3A). Twodimensional-immunoblots provided insight into the response of the $\mathrm{H}_{2} \mathrm{O}_{2}$-mediated oxidative changes. Linking our approach with MALDI-TOF analysis enabled the identification of proteins which are most sensitive to oxidation. Most proteins identified possess oxidation-susceptible Cys and are known to undergo dithiol-disulfide exchange reactions as reported in previous studies (Meyer etal., 2005; Ströher and Dietz, 2008; Lindahl and Kieselbach, 2009). All the identified proteins had functional annotations. Based on their function they can be generally categorized as enzymes involved in carbohydrate metabolism, photosynthesis, redox homeostasis, and nitrogen assimilation (Table 1).

\section{FUNCTIONAL CLASSIFICATION OF IDENTIFIED PROTEINS}

Enzymes such as phosphoribulokinase, GAPDH, and transketolase were identified as primary targets responding to reduction or oxidation of regulatory thiols. They were previously reported to be redox-regulated targets of $\operatorname{Trx}$ (Motohashi et al., 2001; Marchand et al., 2004). RubisCO was identified as one of the primary targets of oxidation. RubisCO plays a major role in photosynthesis, hence it is regulated by several mechanisms and redox-dependent modulation is one of them. Based on our MALDI-MS data analysis (Table 2) two Cys of RubisCO LSU C192 and C427 are predicted to be oxidized. In Chlamydomonas reinhardtii C192 was previously shown to be inactivated by arsenite (Moreno and Spreitzer, 1999). However, site-directed mutagenesis suggested that 
C192 lacks a role in disulphide-mediated inactivation. Rather C449 and 459 are assumed to be involved in redox-dependent catalytic inactivation and to trigger increased proteolysis of the protein (Moreno et al., 2008). In this study the identified C427 is conserved in $91 \%$ of the analyzed photosynthetic organisms (Figure A1 in Appendix). In three-dimensional structures C427, 449 , and 459 are in close proximity with basic rich amino acids, which could be essential for oxidative activity of the protein. Due to the high protein abundance in the millimolar range, RubisCO can be assumed to act as redox buffer to maintain a suitable redox state of the chloroplast in the presence of transiently increased ROS release. RubisCO SSU was identified as thioredoxin target by several studies (Motohashi et al., 2001; Balmer et al., 2003). In this work C41 and 117 were found to be modified by biotin maleimide due to oxidation, although the distance between both Cys is too far from each other (11-25 $\AA$ ) to form a disulfide bond (Taylor and Andersson, 1997). But these Cys might be a target for $\mathrm{SOH}$ oxidation or mixed-disulfide formation and function as oxidant sensor. In Chlamydomonas, Zaffagnini et al. (2012) recently reported 225 glutathionylated proteins, among them many Calvin cycle enzymes, indicating a role of glutathionylation in protecting and regulating chloroplast carbohydrate metabolism. We can exclude glutathionylation, since the proteins were desalted following the reduction with DTT (see Materials and Methods). This step also eliminated any glutathione from the extracts.

In higher plant chloroplasts, Fd-GOGAT is a major enzyme for glutamate synthesis, involved in the conversion of glutamine and 2-oxoglutarate to glutamate. Thioredoxin-mediated redox regulation of Fd-GOGAT was addressed in vitro by several studies (Lichter and Häberlein, 1998; Motohashi et al., 2001; Balmer et al., 2003). The amino acid sequence of the protein shows 24 Cys residues in the mature form, three of which were alkylated with NEM (Table 2). FNR catalyzes the electron transfer between ferredoxin and $\mathrm{NADPH}$, producing reducing equivalents for chloroplast metabolism and thus represents a crucial enzyme for various pathways requiring reductants. The predicted mass of a peptide containing a Cys residue matched the measured mass value $( \pm 0.5 \mathrm{Da})$ suggesting, that this particular Cys is sensitive to oxidation (Table 2). GAPDH is subjected to post-translational modifications which involve thioldisulfide transitions of regulatory Cys, complex formation with ribulose-5-phosphate kinase and a regulatory protein named CP12 (Scheibe et al., 2002). This mechanism allows the coordination of GAPDH redox regulation with availability of its substrate 1,3-bisphosphoglycerate.

Proof of concept is also provided by the identification of 2-Cys Prx and cylophilin 20-3. 2-Cys Prx is among the top 20 most abundant stroma proteins (Peltier et al., 2006), functions as high-affinity thiol-peroxidase (König et al., 2003), and undergoes large redox-dependent conformational changes linked to functional switches (Dietz, 2012). Here the recombinant 2Cys Prx protein was a convincing system to test and validate the various steps of oxidation, blocking, labeling, and detection in the work flow (Figure 2B), and its recovery in vitro and in vivo shows also, that the early oxidizable proteins are indeed trapped with this method (Tables 1-3). Likewise cylophilin

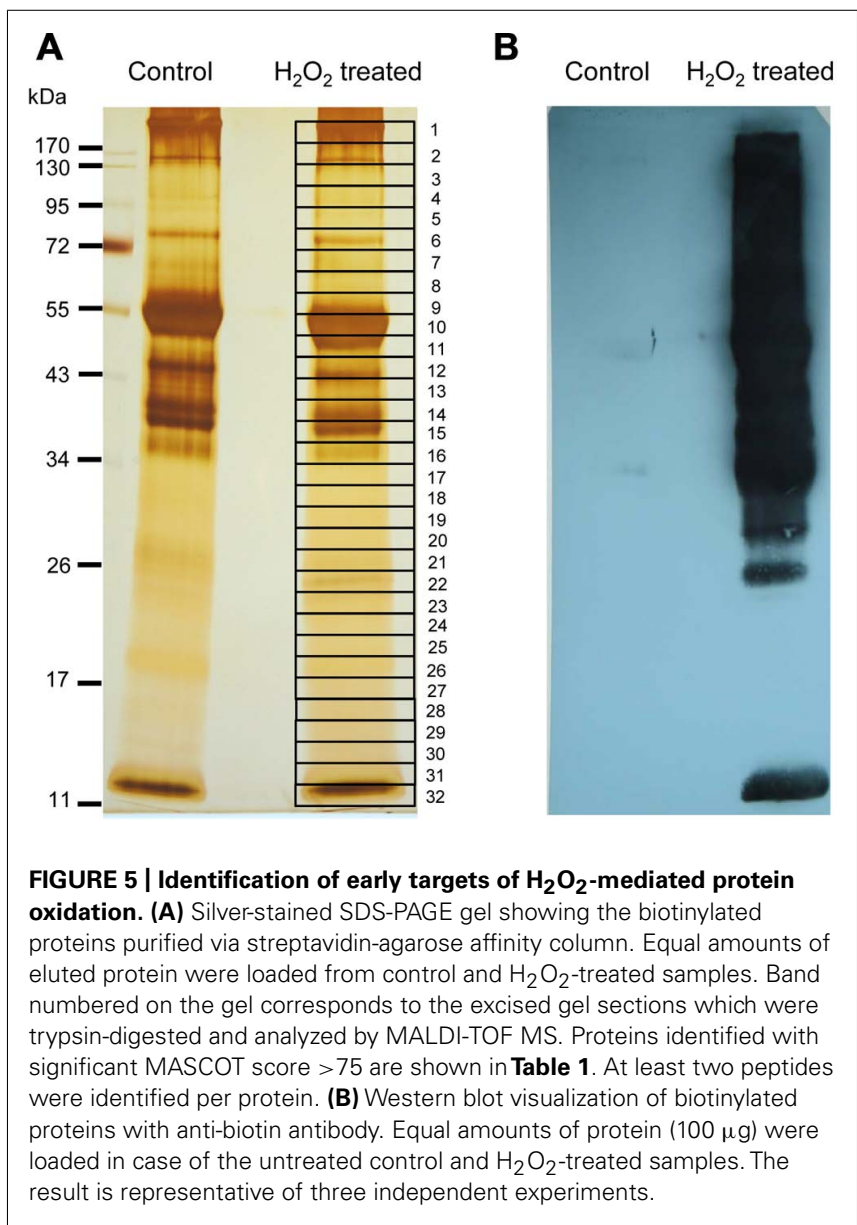

20-3 is a known target of thiol/disulfide transition (Laxa et al., 2007) and this redox switch affects its peptidylprolyl-cis/trans isomerase activity and probably also its capability for protein/protein interactions.

\section{REDOX MODIFICATION OF PROTEINS UPON OXIDATIVE STRESS IN VIVO}

The in vivo redox status of protein thiols was monitored using MV-mediated oxidative stress. The majority of the identified proteins are involved in antioxidant defense (Table 3). GST catalyzes hydroperoxide detoxification in the presence of glutathione. GST tau is also known to detoxify herbicides and plays a role in signal transduction (Neuefeind et al., 1997; Dixon et al., 2003). Thiol-mediated light/dark regulation of Calvin cycle enzymes is a well known process for years (Buchanan, 1980). In this line SBPase and fructose-bisphosphate aldolase were identified. SBPase is activated by disulfide reduction. The involved Cys have been identified by site-directed mutagenesis (Dunford et al., 1998). Interestingly overexpression of SBPase stimulates growth during early development and under stress suggesting that SBPase activity controls fluxes in the Calvin cycle to a major extent (Lefebvre et al., 2005; Feng et al., 2007). The sensitivity of SBPase to oxidation in vivo may provide an explanation why SBPase plays a particular role under stress with increased ROS production. 


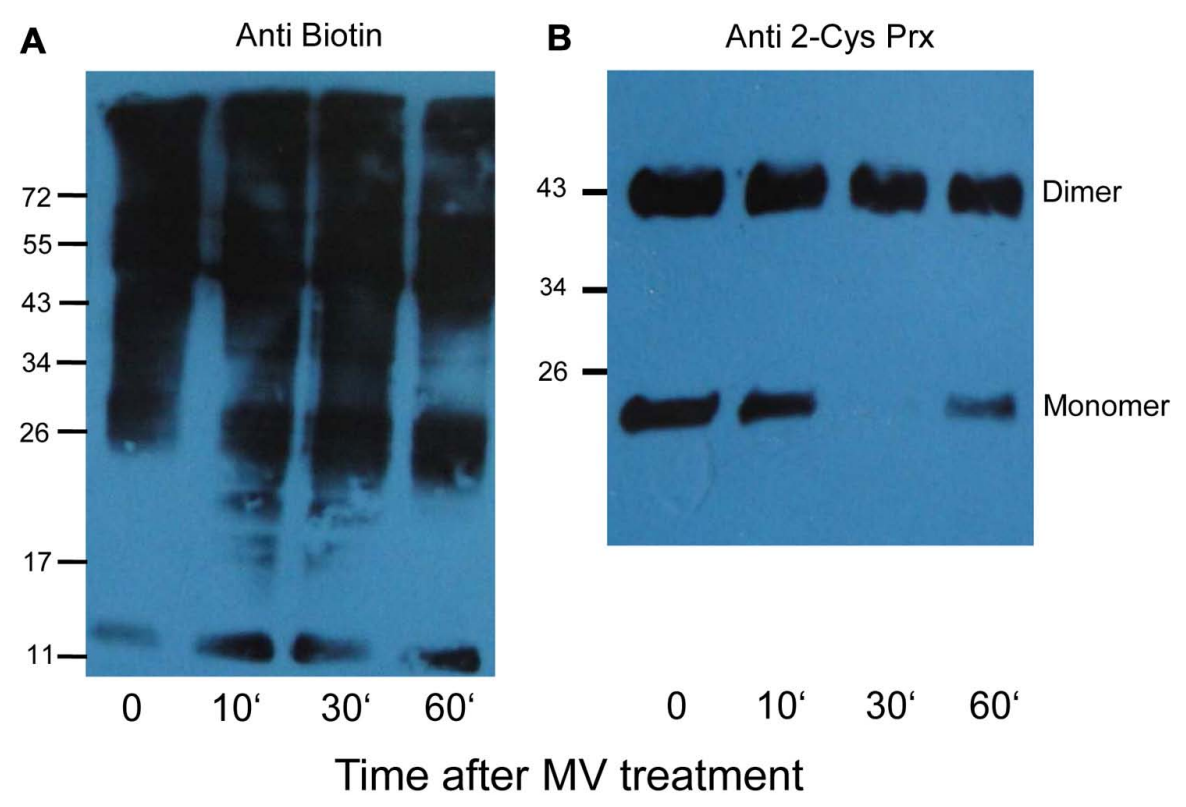

FIGURE 6 | Biotinylated proteins from A. thaliana leaves after methyl viologen treatment. (A) The immunoblot shows increased labeling in protein extracts after treating plants with $50 \mu \mathrm{M}$ MV for different time periods. Control plants $(0)$ were sprayed with water. All samples were extracted in the presence of NEM to block free thiols, then reduced with DTT, and finally labeled with biotin maleimide. (B) The same samples were probed with 2-Cys Prx antibody to determine the redox state of 2-Cys Prx. The oxidized dimer and reduced monomers are indicated.

Table 4 | Cysteines modified upon methyl viologen-mediated oxidation.

\begin{tabular}{|c|c|c|c|c|c|}
\hline \multirow[t]{2}{*}{ No. } & \multirow[t]{2}{*}{ Protein name } & \multirow[t]{2}{*}{ Peptide sequence } & \multicolumn{2}{|c|}{ Predicted mass } & \multirow{2}{*}{$\begin{array}{l}\text { Observed mass } \\
\text { in MV treatment }\end{array}$} \\
\hline & & & NEM & Biotin maleimide & \\
\hline 2 & Myrosinase & $C * S P K I D V R$ & 1113.5 & 1440.0 & $1439.69 *$ \\
\hline 19 & NAD(P)-binding Rossmann-fold-containing protein & SLVSDSTSICGPSKFTGK & 1938.9 & 2265.4 & 1938.1 \\
\hline
\end{tabular}

The table shows the peptide sequence and the predicted mass in the presence of the alkylating agents either NEM or biotin maleimide. The mass observed in

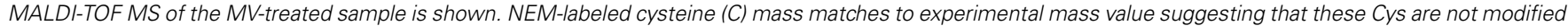

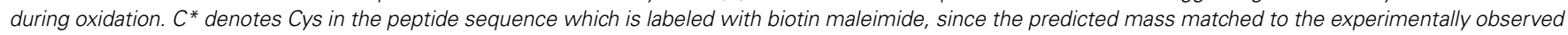
value. The underlined peptides were addressed to be modified also in in vitro oxidation treatment (refer Table 2).

Regulators of PS II oxygen-evolving complex (OEC) such as PsbO-1, PsbP-1, and PsbQ were also identified as oxidationsensitive proteins. A recent study has proposed the presence of an intra-molecular disulfide bond in PsbO-1 and PsbP-1 using a diagonal two-dimensional gel (Ströher and Dietz, 2008). PsbQ indeed has no Cys but could be associated and coeluted with other PS II OEC proteins. Biochemical studies showed that $A$. thaliana nucleoside diphosphate kinase 2 (NDPK2) is associated with MAPK-mediated $\mathrm{H}_{2} \mathrm{O}_{2}$ signaling in plants (Moon et al., 2003). Being one of the early oxidation targets, NDPK2 thiols might play a major role in the ROS-mediated signaling pathway. The in vivo experimental strategy should be improved in the future, e.g., by partial removal of RubisCO, followed by enrichment of less abundant proteins. The here applied method does not distinguish between direct oxidation by $\mathrm{H}_{2} \mathrm{O}_{2}$ and proximity-based oxidation mechanism where thiol proteins such as peroxiredoxins first react with $\mathrm{H}_{2} \mathrm{O}_{2}$ to form a $\mathrm{SOH}$ intermediate, which then oxidizes a thiol of another protein (König et al., 2012).

\section{CONCLUSION}

In conclusion, the here developed approach provides insight into early targets of oxidation by $\mathrm{H}_{2} \mathrm{O}_{2}$ within the stroma proteome under physiologically relevant conditions. This method is applicable to identify redox-dependent protein modifications in vitro and ex vivo, e.g., redox changes upon exogenous MV treatment but also in response to other stresses. The study identified expected early targets such as 2-Cys peroxiredoxin which has been classified as redox sensor and many known targets of redox regulation such as SBPase and FNR. Redox input elements, transmitters, targets, and sensors form the cellular redox regulatory 
network (Dietz, 2008). This network needs to be expanded by the functional element redox buffer proteins. RubisCO is composed of eight LSU and eight SSU. LSU contains 9, SSU 4-Cys residues in A. thaliana. With a concentration of about $500 \mu \mathrm{M}$ RubisCO, the RubisCO thiols represent the largest thiol pool of the stroma that exceeds any other chloroplast compound (Jacquot etal., 2013). A future challenge will be to monitor the diverse thiol modifications such as S-nitrosylation, glutathionylation, and intra- or interpeptide disulfide formation in parallel and to dissect the spatial and functional specificity

\section{REFERENCES}

Allen, J. F. (2003). State transitions a question of balance. Science 299, 1530-1532.

Asada, K. (1999). The water-water cycle in chloroplasts: scavenging of active oxygens and dissipation of excess photons. Annu. Rev. Plant Physiol. Plant Mol. Biol. 50, 601-639.

Balmer, Y., Koller, A., del Val, G., Manieri, W., Schürmann, P., and Buchanan, B. B. (2003). Proteomics gives insight into the regulatory function of chloroplast thioredoxins. Proc. Natl. Acad. Sci. U.S.A. 100 370-375.

Barba-Espín, G., Diaz-Vivancos, P., Job, D., Belghazi, M., Job, C., and Hernández, J. A. (2011). Understanding the role of $\mathrm{H} 2 \mathrm{O} 2$ during pea seed germination: a combined proteomic and hormone profiling approach. Plant Cell Environ. 34, 19071919.

Bartsch, S., Monnet, J., Selbach, K., Quigley, F., Gray, J., von Wettstein, D., et al. (2008). Three thioredoxin targets in the inner envelope membrane of chloroplasts function in protein import and chlorophyll metabolism. Proc. Natl. Acad. Sci. U.S.A. 105, 4933-4938.

Baty, J. W., Hampton, M. B., and Winterbourn, C. C. (2002). Detection of oxidant sensitive thiol proteins by fluorescence labeling and twodimensional electrophoresis. Proteomics 2, 1261-1266.

Bhattachrjee, S. (2005). Reactive oxygen species and oxidative burst: roles in stress, senescence and signal transduction in plant. Curr. Sci. 89, 11131121.

Bienert, G. P., Moller, A. L., Kristiansen, K. A., Schulz, A., Møller, I. M., Schjørring, J. K., et al. (2007). Specific aquaporins facilitate the diffusion of hydrogen peroxide across membranes. J. Biol. Chem. 282, 1183-1192.

Blum, H., Beier, H., and Gross, H. J. (1987). Improved silver staining of plant proteins, RNA and DNA in polyacrylamide gels. Electrophoresis 8, 93-99.
Brandes, N., Schmitt, S., and Jakob, U. (2009). Thiol-based redox switches in eukaryotic proteins. Antiox. Redox Signal. 11, 997-1014.

Buchanan, B. B. (1980). Role of light in the regulation of chloroplast enzymes. Annu. Rev. Plant Physiol. 31, 341-374.

Buchanan, B. B., and Balmer, Y. (2005). Redox regulation: a broadening horizon. Annu. Rev. Plant Biol. 56, 187-220.

Dietz, K. J. (2008). Redox signal integration: from stimulus to networks and genes. Physiol. Plant. 133, 459-468.

Dietz, K. J. (2012). Peroxiredoxins in plants and cyanobacteria. Antioxid. Redox Signal. 15, 1129-1159.

Dixon, D. P., McEwen, A. G., Lapthorn, A. J., and Edwards, R. (2003). Forced evolution of a herbicide detoxifying glutathione transferase. J. Biol. Chem. 278, 23930-23935.

Dunford, R. P., Durrant, M. C., Catley, M. A., and Dyer, T. A. (1998). Location of the redox-active cysteines in chloroplast sedoheptulose1,7-bisphosphatase indicates that its allosteric regulation is similar but not identical to that of fructose-1,6bisphosphatase. Photosyn. Res. 58, 221-230.

Feng, L., Wang, K., Li, Y., Tan, Y. P., Kong, J., Li, H., et al. (2007). Overexpression of SBPase enhances photosynthesis against high temperature stress in transgenic rice plants. Plant Cell Rep. 26, 16351646.

Finkemeier, I., Goodman, M., Lamkemeyer, P., Kandlbinder, A., Sweetlove, L. J., and Dietz, K. J. (2005). The mitochondrial type II peroxiredoxin $\mathrm{F}$ is essential for redox homeostasis and root growth of Arabidopsis thaliana under stress. J. Biol. Chem. 280, 12168-12180.

Foyer, C. H., and Noctor, G. (2003). Redox sensing and signaling associated with reactive oxygen in chloroplasts, peroxisomes and mitochondria. Physiol. Plant. 119, 355-364.

Green, N. M. (1975). Avidin. Adv. Protein Chem. 29, 85-133.

of these modifications under conditions of environmental changes.

\section{ACKNOWLEDGMENTS}

This work was supported by the NRW International Graduate School for Bioinformatics and Genome Research (to Meenakumari Muthuramalingam), the DFG (Di346, FOR 804, FOR 944), and Bielefeld University. We are grateful to Annegret Wolf for technical assistance. Authors also thank Dr. Peter Klein for his scientific discussions.

Halliwell, B., and Gutteridge, J. M. C. (1989). Free Radicals in Biology and Medicine, 2nd Edn. Oxford: Clarendon Press

Jacob, S., and Dietz, K. J. (2009). "Systematic analysis of superoxidedependent signaling in plant cells: usefulness and specificity of methyl viologen application," in Plant Stress Biology: From Genomics to Systems Biology, ed. H. Hirt (Weinheim: Wiley-VCH Verlag), 179-196.

Jacquot, J. P., Dietz, K. J., Rouhier N., Meux, E., Lallement, P. A., Selles, B., et al. (2013). "Redox regulation in plants: glutathione and "redoxin" related families," in Oxidative Stress and Redox Regulation, eds U. Jakob and D. Reichmann (Dordrecht: Springer Science and Business Media). doi: 10.1007/978-94-0075787-5 (in press).

Jaffrey, S. R., and Snyder, S. H. (2001). The biotin switch method for the detection of $S$-nitrosylated proteins. Sci. STKE 86, pl1.

Kaiser, W. M. (1976). The effect of hydrogen peroxide on $\mathrm{CO}_{2}$-fixation of isolated chloroplasts. Biochim. Biophys. Acta 440, 476-482.

Kim, J. R., Yoon, H. W., Kwon, K. S., Lee, S. R., and Rhee, S. G. (2000). Identification of proteins containing cysteine residues that are sensitive to oxidation by hydrogen peroxide at neutral pH. Anal. Biochem. 283, 214-221.

König, J., Lotte, K., Plessow, R., Brockhinke, A., Baier, M., and Dietz, K. J. (2003). Reaction mechanism of plant 2-Cys peroxiredoxin. Role of the $\mathrm{C}$ terminus and the quaternary structure. J. Biol. Chem. 278, 24409-24420.

König, J., Muthuramalingam, M., and Dietz, K. J. (2012). Mechanisms and dynamics in the thiol/disulfide redox regulatory network: transmitters, sensors and targets. Curr. Opin. Plant Biol. 15, 261-268.

Laxa, M., König, J., Dietz, K. J. and Kandlbinder, A. (2007). Role of the cysteine residues in Arabidopsis thaliana cyclophilin CYP20-3 in peptidyl-prolyl cis-trans isomerase and redox-related functions. Biochem. J. 401, 7-27.

Lefebvre, S., Lawson, T., Zakhleniuk, O. V., Lloyd, J. C., and Raines, C. A. (2005). Increased sedoheptulose-1,7bisphosphatase activity in transgenic tobacco plants stimulates photosynthesis and growth from an early stage in development. Plant Physiol. 138, 451-460.

Leichert, L. I., and Jakob, U. (2004). Protein thiol modifications visualized in vivo. PLoS Biol. 2:e333. doi: 10.1371/journal.pbio.0020333

Levine, A., Tenhaken, R., Dixon, R., and Lamb, C. (1994). $\mathrm{H}_{2} \mathrm{O}_{2}$ from the oxidative burst orchestrates the plant hypersensitive disease resistance response. Cell 79, 583-593.

Lichter, A., and Häberlein, I. (1998). A light-dependent redox-signal participates in the regulation of ammonia fixation in chloroplast of higher plants - ferredoxin:glutamate synthase is a thioredoxin-dependent enzyme. J. Plant Physiol. 153, 83-90.

Lind, C., Gerdes, R., Hamnell, Y., Schuppe-Koistinen, I., von Lowenhielm, H. B., Holmgren, A., etal. (2002). Identification of S-glutathionylated cellular proteins during oxidative stress and constitutive metabolism by affinity purification and proteomic analysis. Arch. Biochem. Biophys. 406, 229-240.

Lindahl, M., and Kieselbach, T. (2009). Disulphide proteomes and interactions with thioredoxin on the track towards understanding redox regulation in chloroplasts and cyanobacteria. J. Proteomics 72, 416-438.

Liu, X. P., Liu, X. Y., Zhang, J., Xia, Z. L., Liu, X., Qin, H. J., et al. (2006). Molecular and functional characterization of sulfiredoxin homologs from higher plants. Cell Res. 16, 287-296.

Marchand, C., Le Marechal, P., Meyer, Y., Miginiac-Maslow, M., IssakidisBourguet, E., and Decottignies, P. (2004). New targets of Arabidopsis thioredoxins revealed by proteomic analysis. Proteomics 4, 26962706. 
Marx, C., Wong, J. H., and Buchanan, B. B. (2003). Thioredoxin and germinating barley: targets and protein redox changes. Planta 216, 454-460.

Meyer, Y., Reichheld, J. P., and Vignols, F. (2005). Thioredoxins in Arabidopsis and other plants. Photosynth. Res. 86, 419-433.

Mieyal, J. J., and Chock, P. B. (2012). Posttranslational modification of cysteine in redox signaling and oxidative stress: focus on S-glutathionylation. Antioxid. Redox Signal. 16, 471-475.

Moon, H., Lee, B., Choi, G., Shin, D., Prasad, D. T., Lee, O., et al. (2003). NDP kinase 2 interacts with two oxidative stress-activated MAPKs to regulate cellular redox state and enhances multiple stress tolerance in transgenic plants. Proc. Natl. Acad. Sci. U.S.A. 100, 358-363.

Moreno, J., Garcia-Murria, M. J., and Marin-Navarro, J. (2008). Redox modulation of Rubisco conformation and activity through its cysteine residues. J. Exp. Bot. 59, 1605-1614.

Moreno, J., and Spreitzer, R. J. (1999). C172S substitution in the chloroplast-encoded large subunit affects stability and stress-induced turnover of ribulose-1,5-bisphosphate carboxylase/oxygenase. J. Biol. Chem. 274, 26789-26793.

Motohashi, K., Kondoh, A., Stumpp, M. T., and Hisabori, T. (2001). Comprehensive survey of proteins targeted by chloroplast thioredoxin. Proc. Natl. Acad. Sci. U.S.A. 98, 11224-11229.

Muthuramalingam, M., Dietz, K. J., and Ströher, E. (2010). Thiol-disulfide redox proteomics in plant research. Methods Mol. Biol. 639, 219-238.

Neill, S. J., Desikan, R., Clarke, A., Hurst, R. D., and Hancock, J. T. (2002).
Hydrogen peroxide and nitric oxide as signalling molecules in plants. $J$. Exp. Bot. 53, 1237-1247.

Neuefeind, T., Huber, R., Reinemer, P. Knäblein, J., Prade, L., Mann, K., et al. (1997). Cloning, sequencing, crystallization and $\mathrm{X}$ ray structure of glutathione $S$-transferase-III from $\mathrm{Zea}$ mays var. mutin: a leading enzyme in detoxification of maize herbicides. J. Mol. Biol. 274, 577-587.

Peltier, J. B., Cai, Y., Sun, Q. Zabrouskov, V., Giacomelli, L., Rudella, A., et al. (2006). The oligomeric stromal proteome of Arabidopsis thaliana chloroplasts. Mol. Cell. Proteomics 5, 114-133.

Pfannschmidt, T. (2003). Chloroplast redox signals: how photosynthesis controls its own genes. Trends Plant Sci. 8, 33-41.

Pogson, B. J., Woo, N. S., Forster, B., and Small, I. D. (2008). Plastid signalling to the nucleus and beyond. Trends Plant Sci. 13, 602-609.

Polle, A. (2001). Dissecting the superoxide dismutase-ascorbateglutathione-pathway in chloroplasts by metabolic modeling. Computer simulations as a step towards flux analysis. Plant Physiol. 126, 445-462.

Rouhier, N., Villarejo, A., Srivastava, M. Gelhaye, E., Keech, O., Droux, M. et al. (2005). Identification of plant glutaredoxin targets. Antioxid. Redox Signal. 7, 919-929.

Scheibe, R., and Dietz, K. J. (2012). Reduction-oxidation network for flexible adjustment of cellular metabolism in photoautotrophic cells. Plant Cell Environ. 35, 202-216.

Scheibe, R., Wedel, N., Vetter, S., Emmerlich, V., and Sauermann, S. M. (2002). Co-existence of two regulatory NADP-glyceraldehyde 3-P dehydrogenase complexes in higher plant chloroplasts. Eur. J. Biochem. 269, 5617-5624.

Sethuraman, M., McComb, M. E., Huang, H., Huang, S., Heibeck, T. Costello, C. E., et al. (2004). Isotopecoded affinity tag (ICAT) approach to redox proteomics: identification and quantitation of oxidant-sensitive cysteine thiols in complex protein mixtures. J. Proteome Res. 3, 1228 1233.

Ströher, E., and Dietz, K. J. (2008) The dynamic thiol-disulphide redox proteome of the Arabidopsis thaliana chloroplast as revealed by differential electrophoretic mobility. Physiol. Plant. 133, 566-583.

Tanou, G., Job, C., Belghazi, M., Molassiotis, A., Diamantidis, G., and Job, D. (2010). Proteomic signatures uncover hydrogen peroxide and nitric oxide cross-talk signaling network in citrus plants. J. Proteome Res. 9, 5994-6006.

Taylor, T. C., and Andersson, I. (1997). Structure of a product complex of activated spinach ribulosebisphosphate carboxylase/oxygenase. Biochemistry 36, 4041-4046.

Tietze, F. (1969). Enzymic method for quantitative determination of nanogram amounts of total and oxidized glutathione: applications to mammalian blood and other tissues. Anal. Biochem. 27, 502-522.

Winger, A. M., Taylor, N. L., Heazlewood, J. L., Day, D. A., and Millar, A H. (2007). Identification of intra- and intermolecular disulphide bonding in the plant mitochondrial proteome by diagonal gel electrophoresis. Proteomics $7,4158-4170$.

Zaffagnini, M., Bedhomme, M., Groni, H., Marchand, C. H., Puppo, C. Gontero, B., et al. (2012). Glutathionylation in the photosynthetic model organism Chlamydomonas reinhardtii: a proteomic survey. $\mathrm{Mol}$. Cell. Proteomics 11, M111.01414.

Zhou, L., Bokhari, S. A., Dong, C., and Liu, J. (2011). Comparative proteomics analysis of the root apoplast of rice seedlings in response to hydrogen peroxide. PLoS ONE 6:e16723. doi: 10.1371/journal.pone.0016723

Zrenner, R., Willmitzer, L., and Sonnewald, U. (1993). Analysis of the expression of potato uridine diphosphate-glucose pyrophosphorylase and its inhibition by antisense RNA. Planta 190, 247-252.

Conflict of Interest Statement: The authors declare that the research was conducted in the absence of any commercial or financial relationships that could be construed as a potential conflict of interest.

Received: 21 December 2012; accepted: 28 February 2013; published online: 19 March 2013.

Citation: Muthuramalingam M, Matros A, Scheibe R, Mock H-P and Dietz K$J$ (2013) The hydrogen peroxide-sensitive proteome of the chloroplast in vitro and in vivo. Front. Plant Sci. 4:54. doi: 10.3389/ fpls.2013.00054

This article was submitted to Frontiers in Plant Proteomics, a specialty of Frontiers in Plant Science.

Copyright (c) 2013 Muthuramalingam, Matros, Scheibe, Mock and Dietz. This is an open-access article distributed under the terms of the Creative Commons Attribution License, which permits use, distribution and reproduction in other forums, provided the original authors and source are credited and subject to any copyright notices concerning any thirdparty graphics etc. 


\section{APPENDIX}

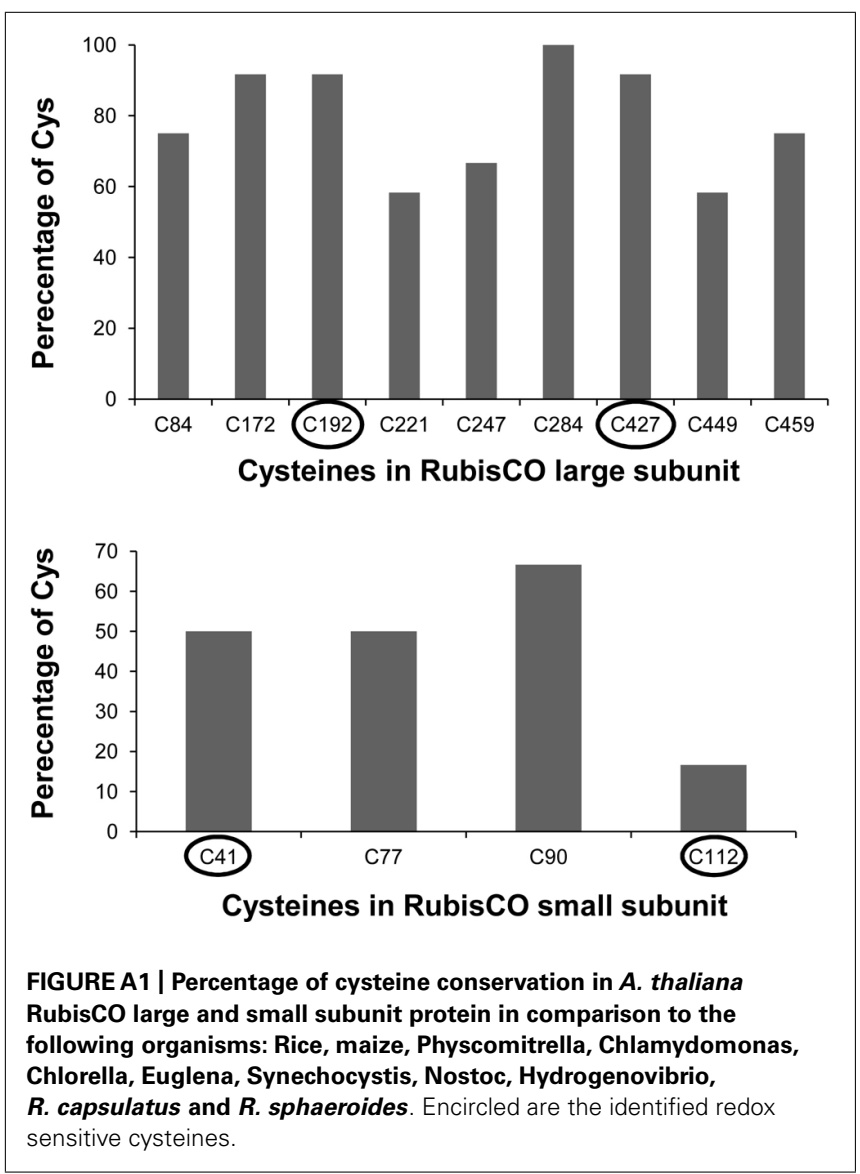

